[2] Sanz I. Nat Rev Rheumatol 2016;12(12):700-2.

[3] Omri HE, et al. Clin Med Insights Blood Disord 2015;8:1-7.

[4] Fervenza FC, et al. Clin J Am Soc Nephrol 2010;5(12):2188-98.

[5] Lahiri M, et al. Best Pract Res Clin Rheumatol 2015;29(2):290-305.

[6] Thiel J, et al. Arthritis Res Ther 2017;19(1):101.

[7] Einarsson JT, et al. Clin Rheumatol 2017; Dec;36(12):2743-2750.

Disclosure of Interest: None declared

DOI: 10.1136/annrheumdis-2018-eular.2982

\section{THU0555 GUIDELINES FOR JUVENILE IDIOPATHIC ARTHRITIS MANAGEMENT: IS THERE A ROOM FOR COMBINED METHOTREXATE AND LEFLUNOMIDE THERAPY IN THE TREATMENT RECOMMENDATIONS}

Y. Atef ${ }^{1}$, H. Lotfy ${ }^{2}$, N. El Aroussy ${ }^{3}$, D. Mekkawy ${ }^{3}$, W. Hassan ${ }^{4}$, S.I. Nasef ${ }^{5}$, G. El Deriny $^{6}$, M. Eissa ${ }^{7}$, Y. Farag ${ }^{2}$, M. El Gaafary ${ }^{8}$, Y. El Miedany ${ }^{3,9}$, on behalf of PRINTO Egypt. ${ }^{1}$ Rheumatology and Rehabilitation, School of Medicine Assiut University, Assiut, ${ }^{2}$ Pediatrics, School of Medicine Cairo University; ${ }^{3}$ Rheumatology and Rehabilitation, School of Medicine Ain Shams University, Cairo;

${ }^{4}$ Rheumatology and Rehabilitation, School of Medicine Banha University, Banha: ${ }^{5}$ Rheumatology and Rehabilitation, School of Medicine Suez Canal University, Ismaillia; ${ }^{6}$ Pediatrics, School of Medicine Alexandria University, Alexandria; ${ }^{7}$ Rheumatology and Rehabilitation, School of Medicine Cairo University; ${ }^{8}$ Community and Public Health, School of Medicine Ain Shams University, Cairo, Egypt, ${ }^{9}$ Rheumatology, Darent Valley Hospital, Dartford, UK

Objectives: To set recommendations for the management of children and adolescents living with JIA and assess whether there is a room for combined methotrexate and leflunomide therapy, adopting treat to target approach.

Methods: the treatment guidelines were developed based on systematic review, local studies, formal consensus and feedback. Initiation of methotrexate or leflu nomide was recommended for polyarticular JIA children who, after 3 month of treatment, did not respond to methotrexate or leflunomide monotherapy, or those whose DMARD dose could not be optimised; a new management step was introduced where a combination of both medications was administered. This was a multicentre study including 76 JIA patients who had been treated with the combination of methotrexate plus leflunomide. All patients were classified according to the International League of Associations for Rheumatology (ILAR) criteria. Recorded data included: demographics, JIA subtype, reason for starting combined treatment, treatment duration, withdrawals, causes of discontinuation, efficacy and safety. Patients were classified as "responders" or "non-responders". Responders were those patients with articular improvement $\geq$ ACR-Paediatric 30 and/or ocular improvement according to the Standardisation of Uveitis Nomenclature Working Group (SUN) definitions. Efficacy was assessed at 3, 6- and 12 month and outcomes were compared to methotrexate monotherapy.

Results: Out of the 76 children there were, oligoarthritis $(34 \%)$, polyarthritis (31\%), systemic JIA with synovitis (>4 joints) $(20 \%)$, and psoriatic arthritis (15\%) Mean age at initiation of combined therapy $10.2 \pm 3.4$ years, mean disease duration is $9.4 \pm 4.8$ months. The combined therapy was superior to methotrexate alone and did not significantly increase the rate of adverse events. ACR-Ped 30 was achieved in $64 \%$ at 3 months, $75 \%$ at 6 months. This was superior to methotrexate alone (37.3\% and $53.8 \% ; \mathrm{p}<0.01$ at 3 - and 6 months respectively). At 1 year $81 \%$ reached Ped 30, 74.5\% reached ACR-Ped 50, 64\% achieved ACR-Ped 70 whereas $51 \%$ met ACR-Ped 90 criteria. There were no serious adverse events. One of the two DMARDs was stopped in $51 \%$ of the children; of them: $25 \%$ were due to adverse events, clinical remission in $25 \%$ whereas $21 \%$ were switched to anti-TNF therapy according to guidelines due to inefficacy or loss of efficacy. All patients who had had uveitis responded well and achieved clinical remission.

Conclusions: For the children with polyarticular JIA who did not respond to monotherapy with methotrexate, combination of methotrexate and leflunomide treatment appeared to be efficacious and maintain a durable response. The current recommendation would be to use combined methotrexate and leflunomide in children with polyarticular JIA who are either intolerant to higher methotrexate doses or who did not have a satisfactory response to methotrexate. The combination should be considered prior to the use of a biologic agent.

Disclosure of Interest: None declared

DOI: 10.1136/annrheumdis-2018-eular.2788

\section{THU0556}

\section{IMPACT OF METHOTREXATE ON GROWTH IN} CHILDREN WITH JUVENILE IDIOPATHIC ARTHRITIS

A. Fazaa, M. Sellami, K. Ouenniche, S. Miladi, S. Kassab, S. Chekili, K. Ben Abdelghani, A. Laatar. Rheumathology, Mongi Slim Hospital - La Marsa, Tunis, Tunisia

Background: Juvenile idiopathic arthritis (JIA) is a heterogeneous group of chronic inflammatory disease which could be responsible for functional impairment and severe growth disturbance. Conventional disease-modifying antirheumatic drugs, such as methotrexate (MTX), may improve growth velocity especially by regulating systemic inflammation.

Objectives: The objective of this study was to evaluate the effect of MTX on growth parameters in pre-pubertal children with JIA and to determine the factors affecting the growth velocity.

Methods: We assessed height and changes in the height standard deviation score (SDS) at disease onset, at the onset of MTX and at the last follow-up visit in a cross-sectional study of JIA children. All patients were pre-pubertal when MTX began and were followed for at least 6 months afterward. We compared growth parameters (height, growth rate, weight and body mass index (BMI)) in responders and non-responders to MTX. The growth rate was defined as the number of millimetres of height acquired during 1 year. Associations between changes in the height SDS and discrete variables were evaluated using chi-square or Fisher's exact tests. The significance level was set at 0.05 .

Results: We enrolled 36 pre-pubertal children with JIA (24 boys and 12 girls) who had been treated with MTX orally. Median patient age was 6.2 years ${ }^{4-13}$ at the onset of MTX and 8.4 years [6.1-14.9] at the latest follow-up. The median disease duration was 2.7 years [2.5-5.3]. Twenty-one patients $(58.3 \%)$ had oligoarticular JIA, 2 patients (5.5\%) had systemic JIA, 10 (27.7\%) had polyarticular JIA and 3 $(8.3 \%)$ had enthesitis-related arthritis. Nineteen children $(52.7 \%)$ had received corticosteroids during an average period of 1.7 years [0.6-3] with a mean of $10 \mathrm{mg} /$ day of prednisone or equivalent. The median duration of MTX at the latest follow-up was 3.1 years [0.62-5.5] with a mean MTX dose of $10 \mathrm{mg} / \mathrm{m} 2 /$ week. $^{10-}$

15 Twenty-eight patients responded to MTX treatment and 8 did not. There were no significant differences between the responders and non-responders for age at treatment initiation, disease duration and mean MTX dose. At MTX onset, no sig nificant differences between the two groups in terms of height $(p=0.52)$, growth rate $(p=0.08)$, weight $(p=0.74)$ and $B M I(p=0.9)$ were found. One year after MTX therapy, mean height $(0.2$ versus $-1.1 ; p=0.03)$, mean growth rate $(0.5$ versus 2.9 SDS; $p=0.01)$, mean weight $(0.4$ versus -2.3 SDS; $p=0.01)$ and mean BMI ( 0.6 versus $-1.9 ; p=0.04)$ were significantly higher in the responder group than in non responders, respectively. At the latest follow-up, this increase was significantly maintained for growth rate $(p=0.001)$ and height $(p=0.002)$ in the responder group. In the multivariate analysis, patients who required more than $10 \mathrm{mg} / \mathrm{m}^{2}$ / week of MTX, systemic JIA and patients with reliance on steroids had a significantly lower growth velocity after the onset of MTX $(p<001, p=0.02$, $\mathrm{p}=0.02$ respectively).

Conclusions: In our study, the increase in growth parameters in pre-pubertal children with JIA was associated with a better control of the disease activity under MTX therapy.

Disclosure of Interest: None declared

DOI: 10.1136/annrheumdis-2018-eular.4767

\section{THU0557 THERAPEUTIC DRUG MONITORING OF BIOLOGICALS IN CHILDREN WITH JUVENILE IDIOPATHIC ARTHRITIS (JIA): AN OVERVIEW OF CURRENT PRACTICE IN ANTI- TNF THERAPY}

A. Nassar-Sheikh Rashid ${ }^{1}$, D. Schonenberg-Meinema ${ }^{1}$, A. de Vries ${ }^{2}$, T. Rispens ${ }^{2}$ T.W. Kuijpers ${ }^{1}$, G. Wolbink ${ }^{2}$, J.M. van den Berg ${ }^{1}{ }^{1}$ Department of Pediatric Hematology, Immunology, Rheumatology and Infectious Diseases, Emma Children's Hospital, Academic Medical Center, ${ }^{2}$ Department of Immunopathology, Sanquin Diagnostic Services Amsterdam, Sanquin, Amsterdam, Netherlands

Background: Juvenile idiopathic arthritis (JIA) is the most prevalent paediatric rheumatic disease. ${ }^{1}$ Long term complications include physical disability and a decreased quality of life. ${ }^{2,3}$ Since the introduction of anti-TNF drugs for JIA, its prognosis has improved significantly. ${ }^{1}$ Personalised medicine is the next step to improve treatment in JIA. Anti-TNF trough levels and demonstration of the presence of anti-drug antibodies (ADA) could help individualise treatment decisions in JIA patients, but evidence supporting this is missing. 